\title{
Quality assurance in education: perception of undergraduate health professions students in a Malaysian university
}

\author{
Hui Meng Er ${ }^{1}$, Vishna Devi Nadarajah ${ }^{1}$, Sook $\mathrm{Han} \mathrm{Ng}^{1}$ and Ann Nee Wong ${ }^{2}$ \\ ${ }^{1}$ Faculty of Medicine and Health and ${ }^{2}$ Quality Improvement Unit, International Medical University, Kuala Lumpur, \\ Malaysia
}

Purpose: Direct student involvement in quality processes in education has been suggested to encourage shared responsibilities among faculty and students. The objectives of this study were to explore undergraduate health professions students' understanding of quality assurance (QA) in education, and identify the challenges and enablers for student involvement in an Asian context. Methods: Twenty semi-structured interviews were conducted among medical, dentistry, and pharmacy students in a Malaysian University. The interviews were audio-recorded, transcribed verbatim, and thematically analyzed to understand the students' perspectives of $\mathrm{QA}$ in education.

Results: The participants recognized the importance of QA towards ensuring the quality of their training, which will consequently impact their work readiness, employability, and quality of healthcare services. Academic governance, curriculum structure, content and delivery, faculty and student quality, teaching facilities, and learning resources were indicated as the QA areas. The challenges for students' involvement included students' attitude, maturity, and cultural barrier. To enhance their buy-in, clear objectives and impact, efficient QA mechanism, and recognition of students' contribution had been suggested.

Conclusion: The findings of this study support student-faculty partnership in QA processes and decision making.

Key Words: Quality assurance, Education, Health professions

\section{Introduction}

Student engagement in quality assurance (QA) is gaining momentum, extending from participation in course and learning environment evaluation, to involvement in structures and process at subject, faculty and institutional level [1]. Institutions that emphasize effective educational practice encourage students to be active participants in their learning [2]. Increased emphasis on the learners' voice is crucial to enhance the collective student learning experience [3]. Students showed moderate to high levels of learning and development as a result of undertaking the representative role [4].

QA in health professions education is critical to ensure that health professional graduates are able to provide quality healthcare services. The World Federation for Medical Education's global standards in medical education include nine areas of evaluation, i.e., mission and objectives, educational program, assessment of students, students, academic staff/faculty, educational resources, program evaluation, governance and administration, and
Received: April 14, 2020 • Revised: June 16, 2020 • Accepted: July 2, 2020 Corresponding Author: Hui Meng Er (https://orcid.org/0000-0001-9835-4840) International Medical University, No. 126, Jalan Jalil Perkasa 19, Bukit Jalil, 57000 Kuala Lumpur, Malaysia

Tel: +60.3.2731.7223 Fax: +60.3.8656.7229 email: huimeng_er@imu.edu.my
Korean J Med Educ 2020 Sep; 32(3): 185-195.

https://doi.org/10.3946/kjme.2020.166

eISSN: 2005-7288

(C) The Korean Society of Medical Education. All rights reserved. This is an open-access article distributed under the terms of the Creative Commons Attribution Non-Commercial License (http:// creativecommons.org/licenses/by-nc/3.0/), which permits unrestricted non-commercial use, distribution, and reproduction in any medium, provided the original work is properly cited. 
continuous improvement [5]. These standards are also endorsed by the World Health Organization, World Medical Association, and International Association of Medical Regulatory Authorities. Students' roles in QA generally include participation in student satisfaction questionnaires, and representation in staff-student committees at course and departmental levels. Students' feedback is important as it guides improvement efforts in education delivery.

On the other hand, Crawford [6] has argued that "performance-led approaches to gaining feedback on the student experience $\cdots$ are at best impersonal, untimely and ineffective and at worst de-skilling and devaluing of professional practice in higher education". In the accreditation of medical education programs in the United States, student leaders are engaged as committee members in the institutional self-study process and they also lead the parallel independent student analysis of the school [7]. Their roles in the independent student analysis include developing and conducting student survey, analyzing survey data, and preparing independent student analysis report which is incorporated into the school's final self-study summary. Besides, the Liaison Committee in Medical Education membership includes final year medical students who play a prominent role in the development and revision of accreditation standards. Similarly, in the United Kingdom, the 'Students' Written Submission' prepared by the student representative bodies forms a part of the institutional audit process by the UK Quality Assurance Agency for Higher Education [8]. This has contributed towards positive relationships between the student unions with their institutions [9]. Varying degrees of engagement of students as informants, observers, experts, and stakeholders in QA have also been reported in other European countries [10]. On the other hand, the multiple roles of students as consumers, co-producers and members of a learning community may lead to tensions in performing the roles, especially if the students and staff are varied in their opinions about the responsibilities associated with these roles [3]. It may also challenge the traditional teacher-student relationship, particularly in an Asian context where the relationship is hierarchical in nature [11].

The objectives of this study were to explore the undergraduate health professions students' understanding of QA in education, and to identify the challenges and enablers for student involvement in QA activities.

\section{Methods}

\section{Ethics approval}

The study protocol was approved by the International Medical University Joint Committee on Research and Ethics (IMU 419/2018). The study objectives and details of the project were explained to participants and written consent was obtained from participants before data collection.

\section{Study setting and design}

The International Medical University (IMU), Malaysia, offers health professions programs including Bachelor of Medicine and Bachelor of Surgery, Bachelor of Dental Surgery, and Bachelor of Pharmacy (Honors). The duration of the medical and dentistry programs are 5 years, and that of pharmacy is 4 years. The students are mainly of Asian ethnicity, with $10 \%$ of the student population being international students. Individual semistructured interviews were conducted with the undergraduate medical, dentistry, or pharmacy students who were in years 1 to 5 . 


\section{Questions}

1 What do you understand about quality assurance of education? What does it mean to you?

2 What do you think are the areas to be evaluated in quality assurance of education?

3 Who do you think are responsible for the quality assurance of education?

$4 \quad$ Do you think students play a role in quality assurance of education? Why?

5 What do you think are the benefits and challenges for students to be involved in quality assurance of education?

6 How can the university support student involvement in quality assurance of education?

7 Do you think students should be rewarded or recognized for being involved in quality assurance of education? If so, how should they be rewarded or recognized?

8 What are the ways the university can enhance student involvement in quality assurance of education?

\section{Participants}

A total of 20 participants (12 females, eight males) aged between 19-25 participated in the study, of which 13 of them were holding or previously held positions as representatives of their cohorts or the university's student representative council. The number of participants in years $1,2,3,4$, and 5 were three, six, three, seven, and one, respectively. Three of the participants were international students (from Africa, Bangladesh, and Australia), the others were local students.

\section{Data collection and analysis}

The interviews were conducted by one of the researchers (H.M.E., the first author), based on a set of pre-determined open questions to explore their understanding of QA in health professions education, QA areas, perceived benefits and challenges, as well as rewards and recognition (Table 1). Each interview lasted between 30 to 45 minutes and was conducted in English. All interviews were audio recorded with the consent of the participants and transcribed verbatim. The interviews were stopped when data saturation was reached.

The thematic analysis method as described by Braun and Clarke [12] was used to analyze the interview data. The researchers are from various disciplines and familiar with the QA process in education: H.M.E. (the first author) and S.H.N. (the third author) are academics in the pharmacy program; V.D.N. (the second author) is a biochemist who teaches in the medical and dentistry programs; and A.N.W. (the fourth author) is a professional staff who manages the education QA activities in the university. In addition, H.M.E. and V.D.N. are trained in education sciences and have roles in facilitating the QA activities in the academic programs in the university. Two of the researchers (H.M.E. and S.H.N.) independently read the interview transcripts repeatedly to become immersed in and intimately aware of their contents. They then independently coded the interviews, following which the codes were discussed and the emerging themes were identified. Subsequently, the investigators (H.M.E. and V.D.N.) discussed the identified themes and checked with the original transcripts to make sure they were grounded in the data. The researchers had regular meetings to review and refine the themes until agreement was obtained on the recurring themes. No new theme emerged towards the end of the study, indicating that all the major themes had been identified.

\section{Results}

Through the thematic analysis, four themes were 
Table 2. Emergent Themes and Sub-Themes Based on Interviews

\begin{tabular}{llc}
\hline \multicolumn{1}{c}{ Themes } & \multicolumn{1}{c}{ Sub-themes } & Total no. of quotes \\
\hline Significance of QA in health professions education & Benchmarking of standard and quality of education & 39 \\
& Graduate work readiness and employability & 36 \\
Areas of QA in health professions education & Academic governance & 13 \\
& Curriculum design and delivery & 41 \\
& Assessment & 12 \\
& Faculty qualification and quality & 13 \\
& Student support & 17 \\
& Graduate competencies & 17 \\
& Education resources & 29 \\
& Student feedback & 13 \\
Challenges of students'involvement in QA in education & Student attitude and maturity & 80 \\
& Cultural barrier & 15 \\
Enablers of students'involvement in QA in education & Clear objectives and impact & 43 \\
& Efficient and effective OA mechanism & 66 \\
& Rewards and recognition & 38 \\
\hline
\end{tabular}

QA: Quality assurance.

extracted: significance of $\mathrm{QA}$ in health professions education, areas of QA, challenges, and enablers of students' involvement in QA. The emergent themes and sub-themes based on the interviews are presented in Table 2.

\section{Significance of $Q A$ in health professions education}

All participants acknowledged that QA in education was important as it assures the quality of their professional training. The sub-themes that emerged on the significance of QA in education were benchmarking of standard and quality of education, graduate work readiness, and employability.

1) Benchmarking of standard and quality of education

QA was viewed as an effort by the university to maintain and improve the quality of education delivery. According to the participants, students considered the university's ranking and rating, recognition, and reputation in their choice of university.
Quality assurance of education $\cdots$ to maintain a certain level of standard in terms of delivering education to a certain group of people to be better in all categories and most of all to improve upon every time. (S1)

It's to standardize education, make sure that it reaches a certain minimum criterion of quality." (S15)

Besides the accreditation status of the program, students expected high quality in the program enrolled in order to justify their financial investment in the degrees. This is consistent with the report by Kandiko and Mawer [13] that students have a consumerist ethos towards higher education.

When students apply for institution and such, we definitely want to get our money's worth. (S6)

\section{2) Graduate work readiness and employability}

The participants highlighted that quality education would equip them with the competencies required for future employment. The list included professional and technical competence, communication, team work, time 
management, lifelong learning skills, ethics, and professionalism. In addition, their competence is necessary to instill confidence in the patients who would receive their care and services.

You give confidence to whom that are receiving the treatment $\cdots$ So it's kind of a boost of confidence for both you and your future customer. (S9)

\section{Areas of $Q A$ in health professions education}

The participants perceived that the university's management including the dean, program director, faculty, academic support staff, and students were collectively responsible for the quality of academic programs. While the dean had the authority to influence the educational experience of the students, the faculty and staff were responsible to ensure that the curriculum was well designed and implemented. Students played an important role in providing feedback to the university, as the quality of their training would consequently impact the quality of the healthcare services provided by the graduates. This demonstrated the students' understanding of academic governance, structures, and processes that underpinned education quality.

All the [survey] information goes to the dean $\cdots$ it's his responsibility to deal in those areas and make sure everything is okay. (S6)

Heads of all the departments [are] the ones that make the final decision and that's implemented by all the lecturers and all the staff. (S20)

With any feedback, the quality of teaching and the quality given by the university can be improved $\cdots$ Further down the road, it can also improve the quality of healthcare given out by professionals. (S3)
They highlighted that an up-to-date curriculum that was well organized, delivered using engaging teaching and learning activities and appropriate learning resources such as books and mannequin training models were crucial. Teaching and learning facilities including experiential learning sites were indicated to be relevant QA areas. Moreover, they also recognized that an assessment system that employed a variety of formative and summative assessment tools played a central role in education QA.

Focus students on updated information, $\cdots$ what's going on right now in the research field $\cdots$ and also supply with enough resources. (S8)

Lecturers only provide guidance to the basic concepts in each topic, the students themselves need to find out more by looking at the topics, whether online or through the research papers or the textbooks to find out more about the topics. (S5)

Opportunity for the students to explore in community settings, attachments $\cdots$ maybe volunteer work in orphanage, old folks home, so we can explore ourselves $\cdots$ and how to communicate and what conditions are they in, what challenges that they' re facing. (S13) What makes the education of the highest quality is the testing system. (S15)

The participants cited that student support and faculty-student rapport contributed to students' motivation in learning. The mentor-mentee system in the university was given as an example of student support, whereby each student was assigned a faculty mentor who acted as the personal tutor to the student throughout the program. Besides qualification, faculty were expected to be able to communicate information in a clear manner.

If this course is led by a very so renowned person, then 
it should be a good program. (S12)

Lecture notes could be done very beautifully, very nicely, so simple, like the ability to deconstruct a difficult method or difficult understanding into bits and pieces. (S1)

\section{Challenges of students' involvement in QA in education}

\section{1) Student attitude and maturity}

According to the participants, not all students could appreciate the objectives and values for involvement in QA. Some perceived university as merely a place to obtain the degree to qualify them for future employment. QA activities such as giving feedback was merely a means to express their dissatisfaction with the program or learning experience.

Students who gave feedback are normally the one who have complaints or issues. (S1)

The participants felt that giving feedback was a futile effort if their expectation could not be met, even though they acknowledged that the university required time to address some of the feedback.

I don' $\mathrm{t}$ think the students are very into giving feedback to the lecturers, because we think, even though we say the thing, we understand that not everything can be improved immediately. (S14)

They also noted that some students could be discouraged by the mismatch between ideal versus realistic expectations. This was not unexpected as students in higher education institutions were reported to have high expectations of the service quality and learning environment based on the notion of "students as consumers" [13,14]. As a result, students' expectations might not be realistic [15].

They were disappointed because maybe they expected more. (S6)

Students' involvement in QA could also be hindered by tedious QA mechanism, such as lengthy questionnaires. This was given as a reason for the low response rate, hence there is a need to improve the questionnaires.

When fill out a form it is actually very time consuming. (S4)

Students' lack of interest and understanding of the objectives and values of QA were also cited as the contributing factors.

They don't think that is important to them. (S5)

\section{2) Cultural barrier}

According to the participants, giving feedback, especially negative comments to lecturers could be challenging for some students, particularly in an Asian context. It could be perceived as a behavior of disrespect and conflict with the lecturers. Some claimed that this was influenced by the Asian upbringing environment which valued adherence to rules. This is especially true in Asian societies where student compliance is prevalent, and students generally do not challenge the teachers' authority [11].

They don't want to disrespect them $\cdots$ we know that they're doing their best so to say straight to their faces is not very nice. (S6)

They might feel like $\cdots$ they cannot offend the lecturers, if not their life [is] going to be miserable. (S7) 
We (are) brought up being quiet, not to voice out and follow the rules. (S9)

\section{Enablers of students' involvement in QA in education}

\section{1) Clear objectives and impact}

Although the participants were aware that their feedback might not benefit them directly, they appreciated the fact that it would benefit their junior peers and help to improve the quality of the program. In the long term, it would be reflected in the quality of healthcare services provided by the graduates.

With any feedback, the quality of teaching and the quality given by the university can be improved $\cdots$ Further down the road, it can also improve the quality of healthcare given out by professionals also. (S3)

It's good for our future generation, the healthcare system will only become better, and not only just maintain like today. (S11)

Besides, participation in QA activities such as course evaluation helped in promoting the students' critical thinking and reflective skills.

For the students who are doing the evaluation, $\cdots$ can show the critical thinking of the students, that the students actually reflected $\cdots$ we need to reflect in order for us to improve. (S19)

\section{2) Efficient and effective QA mechanism}

The participants highlighted that an efficient QA mechanism that enabled open communication between faculty and students without hierarchical barrier helped to facilitate student engagement in QA. This could be achieved by having student representatives in QA committees and processes. As they had good rapport with the faculty, they were often approached by other students to convey their feedback to the faculty.

We [student representative council members] have really good relations with very important people at IMU $\cdots$ so we can actually directly communicate with them very easily, because we know them so well. (S15)

Being the [Vice President], I $\cdots$ bridge between the [university] management and the students. So I know how the students think, but then I also know how the management thinks. (S16)

\section{3) Rewards and recognition}

While the participants supported that the students' efforts in QA in education should be recognized and rewarded, most of them were of the opinion that it was students' responsibility to help the university to improve. Award of certificates for their involvement in QA had been suggested as these could be included in their curriculum vitae $(\mathrm{CV})$.

Certificate is the most practical, can use for our CVs. (S14)

\section{Discussion}

Higher education is envisioned as a ground for public good and positively shaping students to who they are becoming [16]. Hence, student engagement activities that add value to students' transformative experience should be encouraged. Engaging students in QA is aligned with the movement towards "students as partners" (SaP) in higher education [14]. In the student engagement model proposed by Healey and Flint [17], both "partnership in enhancement of quality of learning and teaching" and 
"partnership in learning, teaching and research" are complementary in developing partnership learning communities among faculty and students. Student retention and success have been evident through fostering a sense of community and belonging [18]. Besides, research on $\mathrm{SaP}$ has demonstrated enhanced student motivation and learning, metacognitive development, sense of identity, teaching and classroom experience, graduate attributes, and employability skills [19-21].

This study has revealed that culture plays a role in students' perception and behavior towards education QA. This is consistent with the findings from previous studies that students' reactions to learning environment and evaluation of instructions are influenced by their backgrounds [22,23]. Unlike British students who characterize good teachers by their teaching skills [24], Chinese students pay more attention on the teachers' personal qualities in faculty evaluation [25]. Meanwhile, the Japanese culture prefers an indirect communication mode in educational assessment due to concerns for others' emotion [26]. According to Liu [27], silence is an indirect method of communication that is common and acceptable among Asian students, where opinions are not vocalized even if they disagree with the teachers. This is a face-saving strategy that is adopted out of respect for the teachers and concerns for others. It should be recognized that students' docile behavior can hinder the institutional efforts towards improving the quality of education. Therefore, it is worthwhile for institutions to try culturally appropriate methods to engage with the students on quality issues in education, for example, using small group discussions outside classrooms which have been shown to be more effective in a collectiveoriented culture that predominates in East Asia [28]. Besides, an environment that encourages students to express their opinions and views freely is essential. A reciprocal and collaborative approach between faculty and students, underpinned by respect, trust, and communication has been suggested to remove the traditional hierarchical boundaries between the roles of staff and students [14]. Students' readiness to undertake an active role in QA is also dependent on their attitude, maturity, and personal attributes. These are possible reasons for academic resistance against $\mathrm{SaP}$, which is perceived by some academics to be challenging their existing perceptions of students [29]. These need to be addressed, for example through offering selection and training programs to students who are keen to participate in QA activities, so that the effectiveness of QA would not be compromised. QA student experts' pool which consists of students trained for QA processes by national student unions or QA agencies in some European countries has been shown to be beneficial [10]. With regards to academic resistance against $\mathrm{SaP}$, a top-down managerial approach has been suggested to universalize $\mathrm{SaP}$ to promote mutual learning among the faculty and students [14].

As QA is an institutional level project, participation could be limited to students who are self-confident and have spare time for extracurricular activities [30,31]. To encourage students' involvement in QA, it is important to ensure clear communication of objectives, besides rewards and recognition. An efficient QA mechanism that is supported by suitable governance structure, committees, and processes where faculty and student representatives could engage in collegial discussion and decision making in a non-threatening environment is essential. Direct participation and membership of committees, review panels, and validation have been suggested to affect an institutional-level cultural change that promotes student engagement in quality processes [32]. 


\section{Limitations}

Although the invitation to participate in the study was open to all students, it was possible that the participants who volunteered were students who were more engaged with the university or more motivated towards learning. Their perspectives might not be representative of all types of learners, especially those who were reserved and less proactive. We also realized that there was limited insight obtained from the participants about students' perception of the relevance of QA in education to clinical practice and community health. Although this did not affect the conclusion of the study, it is certainly an area that deserves further investigation as the training of healthcare professionals is critically associated with the quality and standard of healthcare services.

\section{Conclusion}

This study has provided evidences that undergraduate health professions students appreciate the importance and relevance of QA in education. Although the qualitative study was conducted in a Malaysia university involving twenty participants, data saturation was obtained towards the end of the study. The findings could be generalized to other Asian universities with similar student populations. The positive outcomes imply that health professions students' roles in QA can potentially be extended from merely providing feedback to direct involvement in QA governance and audit. The shift from the passive role of "students as consumers" to $\mathrm{SaP}$ provides further opportunities for the development of personal and professional attributes such as professionalism and ethics, problem-solving, teamwork, and leadership skills. Nevertheless, the value of such engagement depends on the individual student's maturity and attitude, hence student support and training are crucial. Furthermore, student participation in QA can be enhanced through clear communication of objectives and an environment that promotes a collegial faculty-student working relationship.

\section{ORCID:}

Hui Meng Er: https://orcid.org/0000-0001-9835-4840;

Vishna Devi Nadarajah: https://orcid.org/0000-0002-7126-7189; Sook Han Ng: https://orcid.org/0000-0002-9552-8523; Ann Nee Wong: https://orcid.org/0000-0002-1312-9247

Acknowledgements: This study was presented in the 12th Jakarta Meeting on Medical Education, organized by Department of Medical Education, Faculty of Medicine Universitas Indonesia on October 19, 2019.

Funding: No funding provided for this research.

Conflicts of interest: No potential conflict of interest relevant to this article was reported.

Author contributions: HME and VDN conceptualized the work, designed the study and interpreted the data. HME and SHN collected and analyzed the data. ANW contributed to the research ideas. All authors were involved in the preparation and revision of the manuscript, and approved the final version to be published.

\section{References}

1. Trowler V. Student engagement literature review. York, UK: Higher Education Academy; 2010.

2. Umbach PD, Wawrzynski MR. Faculty do matter: the role of college faculty in student learning and engagement. Res High Educ. 2005;46(2):153-184.

3. Little B, Williams R. Students' roles in maintaining quality and in enhancing learning: is there a tension? Qual High Educ. 2010;16(2):115-127.

4. Lizzio A, Wilson K. Student participation in university 
governance: the role conceptions and sense of efficacy of student representatives on departmental committees. Stud High Educ. 2009;34(1):69-84.

5. World Federation for Medical Education. Standards. http://wfme.org/standards/. Accessed June 10, 2020.

6. Crawford K. Rethinking the student-teacher nexus: students as consultants on teaching in higher education. In: Neary M, Stevenson H, Bell L, eds. Towards Teaching in Public: Reshaping the Modern University. London, UK: Continuum; 2012:52-67.

7. Association of American Medical Colleges; American Medical Association. The role of students in the accreditation of U.S. medical education programs. https://lcme.org/publications/\#Guidelines--amp--Procedures. Published April 2020. Accessed June 10, 2020.

8. The Quality Assurance Agency for Higher Education. Handbook for institutional audit: England and Northern Ireland. http://dera.ioe.ac.uk/8485/1/Handbook2006.pdf. Published 2006. Accessed June 10, 2020.

9. Bohrer J. The role of the student in quality assurance processes. Paper presented at: Higher Education Close Up 3: International Research Conference; July 24-26, 2006; Lancaster, UK. https://www.lancaster.ac.uk/fss/events/hecu3/ documents/janet_bohrer.doc. Accessed June 10, 2020.

10. Fedeli L. Comparative study of students involvement in quality assurance. https://www.esu-online.org/wp-content/ uploads/2019/01/2016-01-27-Deliverable2_1-v2-en-2.pdf. Accessed June 10, 2020.

11. Ng AK, Smith I. Why is there a paradox in promoting creativity in the Asian classroom? In: Lau S, Hui AN, Ng GY, eds. Creativity: When East Meets West. Singapore: World Scientific Publishing; 2004:87-112.

12. Braun V, Clarke V. Using thematic analysis in psychology. Qual Res Psychol. 2006;3(2):77-101.

13. Kandiko CB, Mawer M. Student expectations and perceptions of higher education. London, UK: King's Learning Institute; 2013.
14. Matthews KE, Dwyer A, Hine L, Turner J. Conceptions of students as partners. High Educ. 2018;76(6):957-971.

15. Mamat NH, Nadarajah VD, Er HM, Ramamurthy S, Pook PC. Student evaluation of the learning environment in an undergraduate pharmacy programme: lessons for educators. Med Teach. 2019 Sep 6 [Epub]. https://doi.org/10.1080/0142159X.2019.1654089.

16. Barnett R. The marketized university: defending the indefensible. In: Scullion R, Molesworth M, Nixon E, eds. The Marketisation of Higher Education and the Student as Consumer. London, UK: Routledge; 2010: 39-51.

17. Healey M, Flint A, Harrington K. Students as partners: reflections on a conceptual model. Teach Learn Inq. 2016;4(2):1-13.

18. Thomas L. Building student engagement and belonging in higher education at a time of change: final report from the what works?: student retention \& success programme. https://www.heacademy.ac.uk/system/files/ what_works_final_report_0.pdf. Published July 2012. Accessed June 10, 2020.

19. McCulloch A. The student as co-producer: learning from public administration about the student-university relationship. Stud High Educ. 2009;34(2):171-183.

20. Cook-Sather A, Bovill C, Felten P. Engaging students as partners in learning and teaching: a guide for faculty. San Francisco, USA: Jossey-Bass; 2014.

21. Dickerson C, Jarvis J, Stockwell L. Staff-student collaboration: student learning from working together to enhance educational practice in higher education. Teach High Educ. 2016;21(3):249-265.

22. Germain ML, Scandura TA. Grade inflation and student individual differences as systematic bias in faculty evaluations. J Instr Psychol. 2005;32(1):58-67.

23. Holloway SD. Concepts of ability and effort in Japan and the United States. Rev Educ Res. 1988;58(3):327-345.

24. Jin L, Cortazzi M. Dimensions of dialogue: large classes 
Hui Meng Er, et al: Quality assurance in health professions education

in China. Int J Educ Res. 1998;29(8):739-761.

25. Ting KF. A multilevel perspective on student ratings of instruction: lessons from the Chinese experience. Res High Educ. 2000;41(5):637-661.

26. Urabe M. Cultural barriers in educational evaluation: a comparative study on school report cards in Japan and Germany. Int Educ J. 2006;7(3):273-283.

27. Liu J. Asian students' classroom communication patterns in U.S. universities: an emic perspective. Westport, USA: Ablex Publishing; 2001.

28. Ho S. Culture and learning: Confucian heritage learners, social-oriented achievement, and innovative pedagogies. In: Sanger CS, Gleason NW, eds. Diversity and Inclusion in Global Higher Education: Lessons from across Asia. Singapore: Palgrave Macmillan; 2020:117-159.
29. Bovill C, Cook-Sather A, Felten P, Millard L, MooreCherry N. Addressing potential challenges in co-creating learning and teaching: overcoming resistance, navigating institutional norms and ensuring inclusivity in studentstaff partnerships. High Educ. 2016;71(2):195-208.

30. Curran R, Millard L. A partnership approach to developing student capacity to engage and staff capacity to be engaging: opportunities for academic developers. Int J Acad Dev. 2016;21(1):67-78.

31. Felten P, Bagg J, Bumbry M, Hill J, Hornsby K, Pratt M, Weller S. A call for expanding inclusive student engagement in SoTL. Teach Learn Inq. 2013;1(2):63-74.

32. Bishop DC, Crawford K, Jenner N, Liddle N, Russell E, Woollard M. Engaging students in quality processes. Enhanc Learn Soc Sci. 2012;4(3):1-6. 